\title{
Sendas Poéticas: Trayectorias de la Educación Ambiental del Grupo Geasur en la Descolonización del Campo Ampliado del Arte
}

\author{
Celso Sánchez \\ UNIRIO (Universidad Federal del Estado \\ de Río de Janeiro, Brasil) \\ Geasur (Grupo de Estudio de Educación \\ Ambiental desde el Sur) \\ Patrícia M. Bevilaqua \\ UFRJ (Universidad Federal de Río de Janeiro) \\ Geasur (Grupo de Estudio de Educación \\ Ambiental desde el Sur)
}

\author{
Bárbara Fortes Campos \\ UNIRIO (Universidad Federal del Estado \\ de Río de Janeiro, Brasil) \\ Geasur (Grupo de Estudio de Educación \\ Ambiental desde el Sur) \\ Bárbara Pelacani \\ UFRJ (Universidad Federal de Río de Janeiro) \\ Geasur (Grupo de Estudio de Educación \\ Ambiental desde el Sur)
}

\section{Resumen}

Los caminos poéticos se trazan, en este artículo, por las relaciones de intercambio entre procesos artísticos e investigaciones académicas de educación ambiental, Palabras clave: Arte, Educación ambiental, Descolonización, Reuniones desarrolladas por el Grupo de Educación Ambiental desde el Sur - GEASUR - en la Universidad Federal del Estado de Río de Janeiro, en Brasil. Identificados con la idea de la ecología del conocimiento, contribuyendo así a la descolonización del conocimiento y el arte, los procesos interdisciplinarios se crean y mejoran mediante acciones y obras que desbordan el compromiso social, la colaboración de artistas y no artistas y, principalmente, se desarrollan la percepción del arte en su estado de encuentro. 
Abstract

Poetic paths: experiences of Environmental Education of the GEASur Group regarding the decolonization of the extended field of the arts

In this article, the poetic paths are traced by the exchange relations between artistic processes and academic researches of environmental education, developed by GEASur (Environmental Education Group from the South), in the Federal University of the State of Rio de Janeiro in Brazil. Identified with the idea of the ecology of knowledge, thus contributing to the decolonization of knowledge and art, interdisciplinary processes are created and enhanced by actions and works that overflow social commitment, artists and non-artists collaboration and, mainly, the perception of art in its state of encounter is developed.

Resumo

\section{Sendas Poéticas: Trajetórias da Educaçao Ambiental do Grupo GEASur na desconolização em um campo expandido do arte}

As sendas poéticas são traçadas, neste artigo, pelas relaçóes de intercâmbio entre processos artísticos e pesquisas acadêmicas de educação ambiental, desenvolvidas pelo Grupo de Educação Ambiental desde o Sul - GEAsur, na Universidade Federal do Estado do Rio de Janeiro no Brasil. Identificados com a ideia de ecologia do conhecimento, contribuindo, desse modo, para a descolonização do conhecimento e da arte, os processos interdisciplinares são criados e melhorados por açóes e obras que transbordam o compromisso social, a colaboração de artistas e não artistas e, principalmente, desenvolver a percepçáo da arte em seu estado de encontro.
Keywords:

Art, Environmental Education, Decolonization, Encounters

Palavras-chaves:

Arte, Educação Ambiental, Descolonização, Encontros 
El arte continúa en su aproximación permanente hacia una verdad cada vez más histórica y cada vez menos trascendente. Un día en un punto en el horizonte, los dos procesos se encontrarán, y luego el arte será la vida, y la vida será arte. (PEDROSA apud OITICICA FILHO, 2013:99)

Buscando los pequeños fuegos de la poética que develan tonos, matices y diversidad entre culturas, paisajes y relaciones socioambientales, el Grupo de Educación Ambiental desde el Sur - GEAsur-, de la Universidad Federal del Estado de Río de Janeiro - Unirio (Brasil)- resuena las temáticas de su investigación académica en exposiciones, procesos artísticos y encuentros interdisciplinarios. Así delinean sendas poéticas para horizontes de creación $y$ tierrexistencia ${ }^{1}$ (STORTTI, 2019) del arte-vida, que brillan en un microcosmos de resistencias, culturas y afectos, y permiten la creación de la imaginación de nuevos mundos y subjetividades diversas.

El concepto de tierrexistencia surge de la observación de la fotografía «Tierra naciente», registrada durante la misión Apolo 8 a la órbita lunar en 1968, y su representación en imagen del pensamiento de Hannah Arendt, quien percibe en el discurso científico la expropiación del ser con respecto a su condición mundana. Aunque irremediablemente unidos a la Tierra, los humanos descubren cómo actuar en la naturaleza terrenal como alienados a ella, trascendentes o, como en esa fotografía, desde la perspectiva del universo, poniendo en peligro el proceso vital y natural del planeta y su humanidad (ARENDT, 2007:275). Esto significa, principalmente, que la investigación y la acción científica, y su reverberación socioambiental, generalmente hace invisible «la textura de las relaciones humanas» (2007: 337) y, por lo tanto, la capacidad para crear historia y alumbrar el sentido de la vida en solidaridad en su tierrumanidad y tierrexistencia. Una solidaridad que, según Morin y Kern, nace de la tierra porque «ningún ser vivo, incluso humano, puede liberarse de la biosfera” (MORIN y KERN 2003:53). O sea, asume la inseparabilidad de la existencia humana de este planeta, de esta Tierra. La humanidad se constituye en ese espacio.

Las acciones de los investigadores del GEASur en el campo de la educación ambiental buscan otro sentido científico; la dirección de las conexiones del ser en su tierrexistencia. Proponen el arte y el proceso artístico como metodología

1 Concepto clave de la investigación del doctorado en Educación de Marcelo Stortti (2019), investigador del Grupo GEASur. Tal concepto por su extrema relevancia para el arte integrado a lo pedagógico se tornó título de una canción escrita por el autor de este trabajo, Celso Sánchez, y de una exposición organizada por todos los autores que será presentada al final. 
para la educación ambiental, no solo en la investigación de campo, sino también mediante la celebración de eventos expositivos. Reúnen instituciones académicas y artistas que se inspiran con la idea de «imaginamundos» - imaginar otros mundos posibles (COSTA, 2019). Integran toda la potencia del pensamiento y la creación que trae la resistencia a una sociedad de control que articula sistemas semióticos que trascienden, o más bien deforman, las subjetividades de dos formas complementarias, según el autor filósofo Peter Pal Pelbart: sujeción económica al capital y sujeción subjetiva a la cultura (PELBART, 2003:8I). El control de la cultura capitalista se basa en el olvido obligatorio de otras existencias a través de un proyecto epistemicida, necropolítico y necropedagógico de colonización global.

La Educación Ambiental desde el Sur, como oposición micropolítica a esta determinación del capital, contempla precisamente las diversidades culturales, políticas y afectivas como potencia de tierrexistencia y de encanto con el mundo mágico y misterioso de la reconexión con la naturaleza, en un movimiento ecopoético y ecopoiético.

El presente trabajo plantea un arte que expresa los sentidos de la tierrexistencia, marcados indeleblemente por la diáspora afro-amerindia, la crítica a la esclavitud, al saqueo y a la expropiación de los territorios, de los saberes y de los cuerpos. Marcados por el diálogo con el conocimiento indígena, la filosofía de resistencia de seres humanos que se entienden a sí mismos como naturaleza. Buscamos el arte que germina desde los márgenes, de las periferias, de los campesinos, de las mujeres, de los invisibles, de los latinoamericanos, de los sin tierra y sin techo.

\section{La descolonización del Arte por la Educación Ambiental desde el Sur}

El presente trabajo parte de la Educación Ambiental desde el Sur: tal perspectiva posiciona los saberes en el tiempo y en el espacio, el conocimiento por lo tanto no es a-histórico o neutral. «El conocimiento es jerarquizado en la sociedad colonial moderna según su importancia en el proceso de acumulación de capital que transforma al hombre y la naturaleza en mercancías» (MENEZES, et al., 2019:75). Conceptuamos la Educación Ambiental desde el Sur como

la que busca «sulear» el ser, el conocimiento, el poder y se opone a la colonialidad, especialmente a la pedagógica, porque ella emerge de las luchas populares, empapadas en el territorio, produciendo pedagogías otras, emergentes, innovadoras y creativas que trabajan desde una perspectiva decolonial. Esta praxis educativa desde el Sur identifica la verticalidad de la colonialidad, busca derrocarla y propone construir una horizontalidad en las relaciones; en el 
aprendizaje que deja de ser individual y se convierte en colectivo; en la construcción de otro conocimiento y en la eliminación del «velo» del encubrimiento de uno mismo, rescatando y construyendo una historia diferente que se oponga a la de los ganadores/colonizadores y descubriendo la pluralidad de mundos y formas de ser, existentes, resistentes y reexistentes, anunciando la urgencia de un mundo donde otros mundos sean posibles (MENEZES, et al., 2019:75)

Cuando basamos una Educación Ambiental desde el Sur situamos nuestro campo de reflexiones en el Sur político, no es apenas un Sur geográfico, en los márgenes y los bordes del mundo capitalista, "cuando hablamos "desde el Sur» estamos posicionándonos en la América Latina. Y, si buscamos pensar "desde a», necesitamos sobretodo pensar "con la» (MENEZES, et al., 2019:65)

La Educación ambiental que se produce en el Grupo GEASur es una Educación ambiental con base comunitaria, que trae en si la transversalidad con temáticas importantes como racismo ambiental y ecofeminismos (SÁNCHEZ, et al., 2020). La Educación ambiental entonces reconoce

que con el descubrimiento de las Americas hubo tanto la racialización de la población mundial, cuanto la creación de las identidades subalternas de negros $\mathrm{y}$ indios, $\mathrm{y}$ la instauración de un conflicto ambiental como mito fundacional de la América Latina (SÁNCHEZ, et al., 2020:157).

Inspirase en Boaventura de Sousa Santos de la ecología del conocimiento (2009:43) que contribuye con la ruptura de la estructura de la idea de que el arte es una creación exclusivamente europea y que todo el distanciamiento, en relación con el origen o la estética, de este contexto histórico, cultural o geográfico debe pasarse por alto como tal, así como casi cualquier construcción de conocimiento y cultura, producida más allá de las líneas abisales del pensamiento occidental moderno. Como ejemplo de esta exclusión histórica, los movimientos europeos muy vanguardistas constituidos en su esencia por desafíos intrínsecos a sus propios modelos, se inspiraron en objetos y estéticas de otras culturas, que no se agregaron como arte al universo y al mercado artístico europeo:

El arte moderno nació del imperialismo... nació de la intervención imperialista en África, por ejemplo. Los naturalistas europeos -los antropólogos de la época- descubrieron en los países africanos actividades culturales de alta calidad, de una calidad extraña. El arte negro que se descubrió en París tenía una gran importancia en el cubismo (PEDROSA apud OITICICA FILHO, 2013:I23). 
Por lo tanto, a pesar de este encuentro estimulante con nuevos mundos, el medio artístico europeo, como los exploradores imperialistas, no ha reconocido los procesos de los pueblos que colonizó, ni intercambió conocimiento con artistas de los territorios «más allá de la línea abisal», sino que solo utilizó sus imágenes y tipologías en movimientos artísticos, que perpetuaron y, por lo tanto, legitimaron, aunque sin darse cuenta, predominantemente el pensamiento y el arte occidentales.

El crítico de arte, pensador y activista político, Mário Pedrosa, en una entrevista en 1977, afirma que la tarea creativa de la humanidad comienza a cambiar de latitud y ya no está en las vanguardias "que ya nacen cansadas» (PEDROSA apud OITICICA FILHO, 20I3:II6). La fuerza creativa está en los movimientos de resistencia a los valores hegemónicos y capitalistas (2013:I50) capaces, por lo tanto, de delinear un nuevo arte, manifestado en las

Caras más vitales de este prisma revolucionario en gestación, en las entrañas convulsivas de los pueblos que Fanon ${ }^{\mathrm{T}}$ llamó 'los condenados de la tierra', y que parten de un punto metodológico necesario para escapar del lujo estético del hemisferio norte y emerger de nuestros mundos desheredados (PEDROSA apud OITICICA FILHO, 2OI3: IIO).
La transformación, el cambio y la imaginación de nuevas realidades y nuevas subjetividades son el territorio común entre los dos campos de acción (arte y educación) que, aunque separados como disciplinas, se cruzan permanentemente en la práctica, especialmente con otros grupos o comunidades. En el libro «Sostenibilidad y educación: una mirada a la ecología política» de 20I2, el educador Carlos Frederico Loureiro sugiere dinámicas del universo del arte, involucrando la dimensión sensorial, la percepción y la corporeidad como actividades esenciales para la emancipación porque

Sirven para demostrar que los aspectos perceptivos y lúdicos también son importantes para una práctica crítica en la educación ambiental y, al mismo tiempo, destacando que la reflexión sobre la sociedad es una parte constitutiva de estos componentes que a veces los educadores y las educadoras tratan como algo separado de las relaciones sociales, reforzando una dualidad entre razón y afecto o entre cuerpo y mente (LOUREIRO, 2OI2:94).

El arte exhibido y a menudo creado por las propuestas de GEASur busca la mirada y el «sentipensar», propuesto por el sociólogo Fals Borda, de los «Condenados de la tierra» de Franz Fanon, ${ }^{2}$ encarnados por cada artista e investigador 
que busca otros significados para existir y ser más allá de la colonialidad y sus subjetividades. Un arte post-abisal que dibuja una brújula que apunta hacia el Sur, como en el trabajo de Joaquín Torres García, para donde las miradas, las intenciones y las posibilidades de construir utopías alcanzables pueden dar la bienvenida a todos los que sueńan con un mundo donde encajen muchos otros mundos posibles.

\section{Arte Socialmente Comprometido: Un campo expandido en Brasil}

El entrelazamiento con el arte aparece durante la realización de las investigaciones basadas en la comunidad realizadas por el Grupo GEaSur, en momentos de intercambio y de creación colectiva, de películas, fotografías, dibujos, pinturas o esculturas sociales. Procesos de subjetivación que, en las palabras del geógrafo Milton Santos, re-significan el lugar del mundo como un espacio de «acontecer solidario» (2006:I09). Las acciones socioambientales en un campo ampliado del arte, en el que se desborda el compromiso social, la interdisciplinariedad, la participación y colaboración de artistas y no artistas, y especialmente la percepción del arte en su estado de encuentro. Una elaboración pedagógica y artística que propone deconstruir los muros de museos, disciplinas, galerías, universidades y los muros invisibles, que inhiben la circulación y la actuación de una gran parte de la población en estos campos, llevando el proceso creativo y cognitivo al lugar de la vida, de la educación informal y del diálogo. Contribuyendo a la formación de protagonismos tanto en el universo de la creación simbólica, como en las elaboraciones y re-creaciones sociales y ambientales concretas, a través de la reinvención de la autopercepción, de autonomía y también mirando al mundo, a lo largo de una perspectiva de "transversalización capaz de pasar del campo del arte a la ética, del abrazo de la otredad misma al abrazo de otros» (KASTRUP, 2008:I28).

El campo expandido del arte, por lo tanto, se entrelaza con la pedagogía crítica en un movimiento llamado Arte Socialmente Comprometido, que, según el educador, artista y curador mexicano Pablo Helguera, se define como «a dependencia de las relaciones sociales como un factor esencial para su existencia» (20II:35) $\mathrm{y}$ «por su interés en crear un impacto significativo en la esfera pública» (20II:37). Consciente de las contribuciones de la pedagogía crítica a esta práctica social del arte, Helguera considera que es un desafío saber cómo puede continuar contribuyendo a revitalizar el arte (2012:I).

Miramos cómo en la confluencia entre la práctica artística y el campo pedagógico están las propuestas del colectivo argentino Ala Plástica, una organización ambiental y artística con sede en la cuenca del río de La Plata. Desde 
I991, Ala Plástica ha desarrollado una práctica de arte que piensa el territorio como un aspecto vital de la comunidad y lleva a cabo iniciativas artísticas de colaboración con las poblaciones locales, fortaleciendo el diálogo y la comunicación. Crean obras de arte, gestionan la regeneración de las redes económicas locales y estimulan experiencias colectivas para una influencia más grande en su propio espacio social, cultural, político y biológico. El colectivo combina intervenciones directas en el campo con la colaboración de lugareños, otros artistas, científicos y grupos ambientales, estableciendo la reunión de participantes en un ambiente propicio para la creación de sentidos, percepciones y acciones que pueden contribuir, como experiencia, a «reactivar el saber del cuerpo extrapersonal, intensivo y estético del mundo" (ROLNIK, 20I5), enredando así el proceso artístico en el dominio de las intersubjetividades, la política y la intervención socioambiental.

El compromiso de los participantes ocurre con la inmersión en este proceso de creación. El pensamiento y el debate público se convierten en el material central y el núcleo constitutivo del trabajo, que involucra a un colectivo social o, a veces, a toda la población de una región en la escenificación de microutopías de interacción humana. Estas microutopías constituyen un movimiento cultural enfocado más en la creatividad social que en la autoexpresión (ALA PLÁSTICA, 20I5:57).
En Brasil, la artista Paula Trope también desarrolla continuamente el arte socialmente comprometido. En 2005, Trope enseña a los niños de Morrinho, en el barrio de Laranjeiras, en Río de Janeiro, a disparar con cámaras estenopeicas (pinhole) y en colaboración con ellos una serie de fotografías, titulada Sem Simpatia, aludiendo a una expresión popular y local, lo que significa sin pretensiones ni mentiras. El resultado de este trabajo se mostró en la Bienal de São Paulo de 2007, en retratos de estos jóvenes artistas, ampliados en grandes formatos y acompañados de un dibujo en el piso de un mapa de la favela de Pereiráo. Las fotos revelan sus identidades y la comunidad a la que pertenecen y se reconocen mutuamente, revelando un proceso de conocimiento y afecto compartido.

También presentado en la Bienal de São Paulo de 2007, que promovió exposiciones y el debate sobre el arte en contextos sociales, la artista y arquitecta eslovena, Marjetica Potrc, en colaboración con el colectivo Nicolas Krupp Contemporary art, con el gobierno de Acre, en Brasil y con la población local, desarrolló el proyecto Acre: Escuela rural, llevado a cabo en la selva amazónica. Potrc investiga principalmente los problemas relacionados con la expansión urbana y los cambios posteriores en la vida cotidiana, prestando atención al proceso de desarrollo de las ciudades en contraste con el aumento de la pobreza, las tragedias 
ecológicas y los conflictos geopolíticos y, en el proyecto Acre: Escuela rural, agrega la tipología de la arquitectura local, el conocimiento y las demandas de los habitantes del lugar, equipando a la escuela con paneles de energía solar en el techo del gallinero y antena parabólica. Después del horario escolar, la escuela sirve como centro comunitario, espacio para reuniones y acceso tecnológico, beneficiando a toda la aldea.

Las obras de artistas socialmente comprometidos, por lo tanto, están constituidas por esta reunión de fuerzas, que resulta, a través de diálogos, fotografías, cartografías, dibujos, textos y otras formas de comunicación e «información, que hoy se transforma en el verdadero instrumento de unión entre las diversas partes de un territorio» (SANTOS, 2006:109), en numerosos registros de significados y interacción discursiva. El proceso de compartir experiencias y conocimientos «aumenta la oportunidad para que cada persona transforme cada momento de su vida en un momento de aprendizaje, participación y cuidado" (ILLICH, I985:I4), dando visibilidad a las singularidades de las expresiones culturales silenciadas o ignoradas por una cultura hegemónica, y proponiendo procesos artísticos que escapan a la autonomía formal y se mueven a un estado socialmente comprometido y conectados a una práctica pedagógica crítica y transgresora, que piensa en la rearticulación de las relaciones interculturales y ambientales, contribuyendo así a la reunión del lugar de lo «posible», buscado por el educador Paulo Freire:

Estar en el mundo sin hacer historia, sin por ella ser hecho, sin hacer cultura, sin «tratar» su propia presencia en el mundo, sin soñar, sin cantar, sin musicar, sin pintar, sin cuidar la tierra, las aguas, sin usar las manos, sin tallar, sin filosofar, sin puntos de vista sobre el mundo, sin hacer ciencia, o teología, sin asombro frente al misterio, sin aprendizaje, sin enseñanza, sin ideas de formación, sin politización no es posible (FREIRE, 1996:24).

Trazando una breve historia, desde la década de 1960 en adelante, algunas producciones artísticas comenzaron a empeñarse en la participación del público y en el énfasis del proceso creativo en lugar del producto terminado, así la obra de arte se abre en un aspecto que desborda los límites de los modos de fruición, mirada e interpretación del espectador. El artista Hélio Oiticica desarrolla esta perspectiva en el ensayo Apolicapopótese (1968:I), en el que cuestiona la idea de "obra» y sugiere el término "proposición», entendiendo que el arte no debe limitarse a productos de representación, pero también buscando transformaciones y afectos comportamentales (1968:3). En medio de la cultura popular de Río de Janeiro, durante su experiencia en la favela de Mangueira en Río 
de Janeiro, en 1964, Oiticica se convirtió en uno de los precursores del arte como estado de encuentro y, de inmediato, transgredió los modos de producción, difusión y apreciación del arte, con una obra abierta al movimiento, al ritmo, al paisaje, a la sinuosidad y a la sensualidad de las relaciones humanas. Desarrollando un arte inseparable de las cuestiones sociales a través de la experiencia artística de los Parangolés, «estableciendo un vínculo entre la poesía de la vida y la ética» (PROENÇA, 2OI2:263).

$\mathrm{Al}$ mismo tiempo, Augusto Boal crea el Teatro de los Oprimidos y piensa en la democratización y socialización de los medios de producción teatral y el acceso a este arte por parte de las capas sociales menos favorecidas, proponiendo la transformación de la realidad social a través de diálogos y talleres, esencialmente relacionados con la pedagogía de los oprimidos del educador Paulo Freire. Esta democratización del arte también es evidente en sus espectáculos, como en una de sus obras más conocidas, Show Opinión, cuando Boal reunió a la artista símbolo de la bossa nova Nara Leáo, y los compositores y sambistas Zé Keti y João do Vale, entre canciones y narrativas, abordando los problemas del país y la recién establecida dictadura brasileña. Curiosamente, meses después, en el mismo año de 1964, se realizó la primera presentación pública de la cantante y residente de la favela de Mangueira, Clementina de Jesús, junto al guitarrista clásico Turíbio
Santos, en una reunión entre lo clásico y lo popular. Diseñado y producido por el compositor y poeta Hermínio Bello de Carvalho en el espectáculo $\mathrm{O}$ Menestrel. A pesar de la represión en el país, hubo una coyuntura de posibilidades e intercambios entre el campo del arte y la sociedad y una intensa porosidad entre las manifestaciones culturales de elite y populares, que cambiaron enormemente las relaciones jerárquicas, especialmente en relación con el valor y el reconocimiento entre cultura $\mathrm{y}$ arte popular y erudito.

Según el historiador de arte Grant $\mathrm{H}$. Kester, los artistas socialmente comprometidos "colaboran con individuos y grupos de otras subculturas sociales y políticas o producen junto con grupos activistas, ONG y asociaciones de vecinos (KESTER, 2006:II). Esa propuesta crea un movimiento de tejer la deformación entre el arte, la pedagogía crítica y la sociedad, rompiendo las convenciones del medio artístico y cambiando los procesos artísticos al territorio común. En el sentido del lugar público habitual y el intercambio, provocando una experiencia de pensamiento «donde las fuerzas activas de la libertad creativa puedan controlar las fuerzas reactivas de la dominación cultural, creando así nuevas formas de percepción y existencia en el mundo" (ULPIANO, 1988). Una existencia y un conjunto de experiencias colectivas que exigen no solo la satisfacción de las necesidades básicas, sino también el «pleno 
desarrollo de las facultades de los seres humanos y el cumplimiento de sus aspiraciones morales, intelectuales, afectivas y estéticas, a través de la reconstrucción del ambiente constitutivo de los mundos y vidas de personas» (LEFF, 2009:290).

\section{Sendas Poéticas en Educación Ambiental Creadas por GEASur}

Los caminos poéticos trazados por GEASur se unen con el arte socialmente comprometido en su propuesta de crear nuevas realidades, subjetividades, esculturas sociales y arte popular en contextos sociales de los procesos colaborativos en educación ambiental, como se lleva a cabo en los proyectos que siguen. Presentamos a seguir trabajos pedagógico-artísticos resultados de los encuentros de los estudiantes de maestría y doctorado, además de investigadores de GEASur, con los territorios y sus luchas sociales.

\section{Museo de las Remociones: Rio de Janeiro/BR}

El itinerario a través de las sendas poéticas concebidas por el grupo de investigaciones geaSur parte de los procesos de educación ambiental crítica para encontrar el arte en este campo expandido, del cual emergen encuentros y diálogos que proporcionan fuerza a la creación colectiva, tanto en el universo simbólico como en la transformación socioambiental. La investigación desarrollada por el grupo nos llevó a conocer también los movimientos sociales que utilizan el arte y la afirmación de sus culturas como un instrumento para mantener sus historias que representan la reacción a un sistema que disloca obligatoriamente sus existencias, como es el caso del Museo de las Remociones en la Vila Autódromo. ${ }^{3}$

La presencia de la comunidad en las cercanías del sitio elegido para la construcción del Parque Olímpico, para los Juegos Panamericanos de 2007, representó una estética que el gobierno no quería transmitir en todo el mundo, además de que el área estaba en la dirección del vector de valorización inmobiliario de la ciudad. La comunidad fue elegida como una "zona de sacrificio» ${ }^{4}$ (ACSELRAD, H., 2005) a favor de los intereses del mercado que diseñó la eliminación de residentes y condujo a la desterritorialización

3 Vila Autódromo, un asentamiento establecido en la ciudad de Río de Janeiro durante más de 40 años y ubicado en el barrio de Jacarepaguá, fue objeto de un conflicto a causa de su territorio, y durante más de una década reaccionó activamente a los decretos de expulsión y luchó por la visibilidad de sus reclamaciones.

4 Designa localidades que destacan por su concentración de prácticas ambientalmente agresivas y que influyen en los procesos de desterritorialización de las poblaciones locales y la vulnerabilidad de estos grupos. Fuente: ACSELRAD, H. (2005). 
de más de 500 familias. Hoy solo quedan 20 casas, lo que representa solo el $3 \%$ de lo que fue Vila Autódromo.

En 20I6, con objetivo de mantener la memoria de la resistencia de la comunidad, se creó el Museo de las Remociones, un espacio al aire libre con las esculturas en tributo de las casas demolidas, hitos del proceso violento por el que lo pasaron. El Museo de las Remociones surge de una fuerte articulación entre Vila Autódromo y las universidades que trabajaron con la comunidad, representando un espacio diseñado para "participar en la lucha contra las mudanzas, preservando la conexión simbólica, la memoria emocional y las prácticas sociales de las comunidades removidas» (MUSEO DE LAS REMOCIONES, 20I8).

Este proyecto perdura y se manifiesta como una acción continua de resistencia que lucha contra la invisibilidad de los recuerdos de la Vila Autódromo, además de representar todas y cada una de las comunidades en proceso de eliminación por los procesos contemporáneos de colonización del capital. El museo está dirigido por residentes, pasantes e investigadores de diversas áreas y universidades de Río de Janeiro y recibe visitas de investigadores de todo el mundo, habiendo alcanzado una visibilidad considerable. Fundado el I8 de mayo de 2016 (Día Internacional de los Museos), el Museo comienza con la construcción de siete esculturas hechas con escombros (Fotos I, 2 y 3). Cada obra de arte de la exposición representa un espacio o momento significativo rescatado por los residentes a través de talleres de memoria y dela construcción de mapas afectivos.

En su Plan Museológico, la comunidad hace explícito el espacio como herramienta para luchar contra las mudanzas:

El Museo de las Remociones tiene la función de ser un instrumento de resistencia y lucha en todas las comunidades locales y nacionales que sufren procesos de remoción y prácticas especulativas, promoviendo así la visibilidad de la causa, para evitar nuevas acciones arbitrarias y el consiguiente borrado de la memoria (MUSEO DE LAS REMOCIONES, 20I8:s/n).

En cada visita recibida, los residentes presentan las obras y cuentan la historia del pueblo a través de un discurso de quienes vivieron todo el camino de lucha que ha generado la colección. El conjunto de obras y la actuación del museo revelan la condición histórica de la comunidad como agentes que pertenecen y transforman su territorio y también apuntan la necesidad de mantener y difundir esta historia. Este es un hecho importante cuando se observa a la luz de la educación, ya que significa la comprensión de uno mismo como individuo integrante de un sujeto colectivo. Así, es posible reconocer que los sujetos son productores de conocimientos que son extremadamente relevantes para su entorno. 

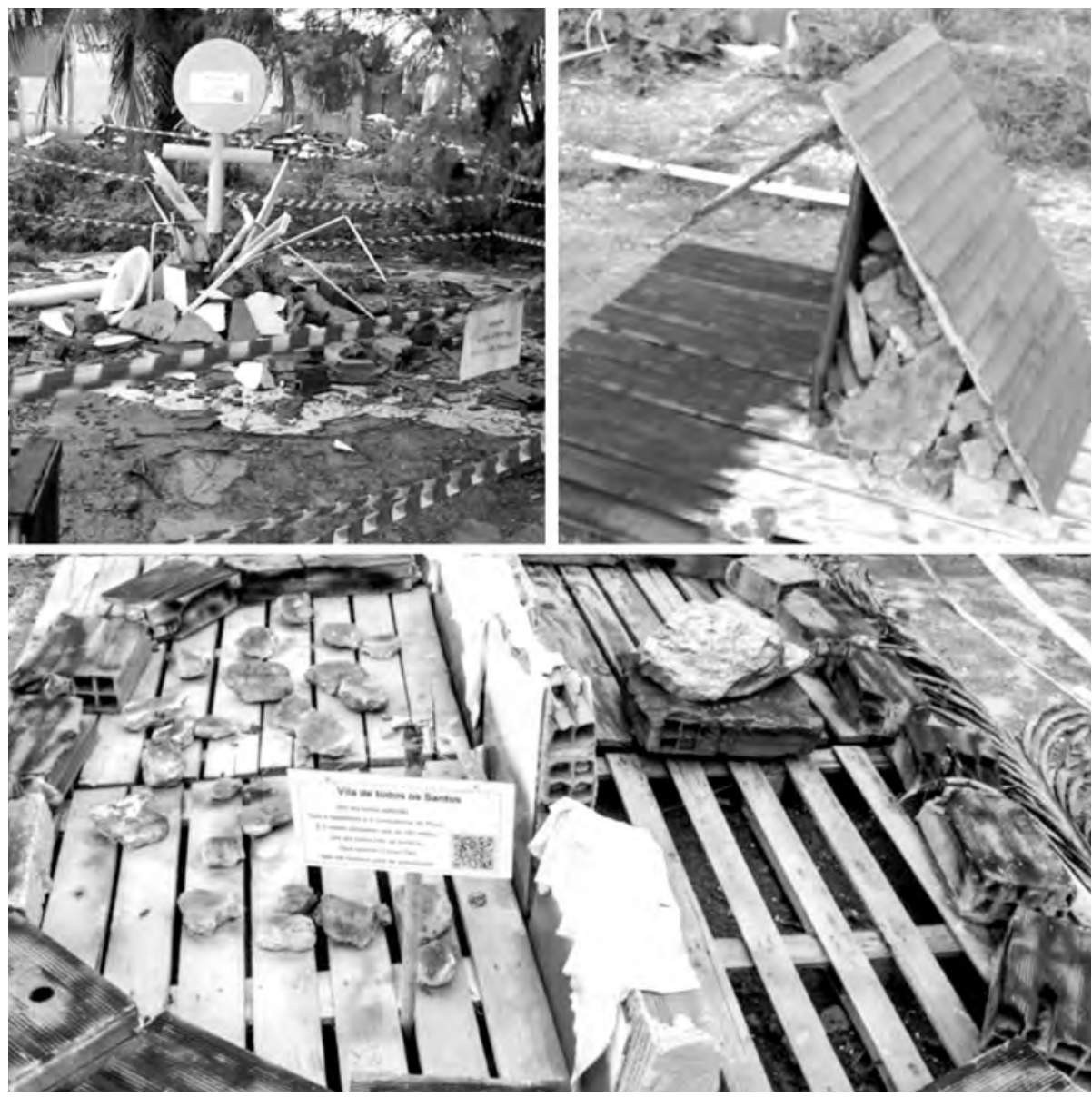

Figuras 1,2 y 3. Museo de las Remociones. Escultura "Vila de Todos los Santos", un homenaje a la casa de doña Heloísa Helena (Fuente: museudasremocoes.com/esculturas/)

También demuestra la conciencia de la dinámica de los poderes e intereses a los que están sometidos. Los procesos de memoria y resistencia continuos representan una relevancia fundamental en el mantenimiento de su cultura.

En particular, el Museo representa efectivamente el aspecto «desterritorializador»
(HAESBAERT Y BRUCE, 2002) del estado al ignorar las territorialidades de esos sujetos, tratando de sacarlos de sus territorios, tratando lo residentes con desprecio, cuando dependería de ellos brindar asistencia y garantizar los derechos. Las obras diseñadas por los residentes revelan su resistencia al proceso de invisibilización 
de la comunidad, llamando la atención también sobre el sentimiento de «pérdida de identidad» que sintieron los que fueron expulsados de Vila Autódromo.

El discurso de los residentes de la comunidad también dice que con la lucha contra la remoción «conocían un lado de la ciencia que no conocían». Enfatizan que hasta entonces no sabían que ellos mismos eran seres históricos, que sus historias podían contarse un museo porque habían aprendido que solo las personas importantes y de grandes hechos tienen este reconocimiento. Pero, a diferencia de todas estas afirmaciones, la lucha había enseñado que todos los residentes de la Vila son personas importantes, que pueden y deben tener un museo que contenga sus historias, su legado para resistir a la expulsión de su propio territorio. Fue a través del Museo y de las obras exhibidas allí que los residentes marcaron su resistencia. (FORTES, 2019)

El enfoque de GEASur en la comunidad de Vila Autódromo es debido el reconocimiento del Museo de las Remociones como resultado de la lucha de los residentes que, por su propia naturaleza, se configura como una herramienta educativa importante. Aunque en el principio, el propósito de la resistencia era permanecer en sus hogares, desde la creación del $\mathrm{Mu}$ seo, el movimiento asume una intencionalidad educativa, y lo hace a través del arte, al exponer sus trayectorias basadas en obras que representan estas memorias.
Además de eso, el Museo de las Remociones se convirtió en el tema de una de las disertaciones de GEASur, por parte de la investigadora Bárbara Fortes, el grupo también entiende esta interlocución como una importante interposición pedagógica, defendiendo su presencia en el entorno académico como esencial. Por lo tanto, los residentes de Vila Autódromo también estuvieron presentes como expositores en la $3^{a}$ edición del Curso de Extensión «Educación Ambiental Basada en la Comunidad y Ecología Política en América Latina», celebrado en 2019 en la Universidad Federal del Estado de Río de Janeiro - UNIRIo. En esa oportunidad, doña Penha, importante figura de resistencia, habló con los estudiantes, y junto con otras personas de la comunidad, presentó una exposición fotográfica y poética acerca del Museo de las Remociones.

\section{Leyendas, Oraciones y Botellas: Educación Ambiental Basada en la Comunidad y Conocimiento Local en el Valle de Jequitinhonha}

A partir de 20I2, cuando el investigador Daniel Renaud llegó al Vale do Jequitinhonhaa a través de un proyecto social, comenzó un proceso de investigación que se ha extendido hasta nuestros días, y que se formalizó a través del trabajo de pregrado llamado «Cuentos, Bendiciones y Mezinhas: Educación ambiental popular como estrategia para la protección de los saberes locales» (RENAUD, 20I4); 
la tesis de maestría llamada «Leyendas, oraciones y botellas: educación ambiental de base comunitaria y conocimiento local en el Vale do Jequitinhonha» (RENAUD, 2017); y que hoy se ha profundizado en una tesis doctoral.

A través de un estudio del medio ambiente, agregado a una encuesta bibliográfica de la región, además de conversaciones con residentes de las comunidades, identificadas como maestros del conocimiento local, se revelaron situaciones que condujeron a discusiones colectivas y preguntas sobre la realidad local. De la investigación de campo surgieron tres categorías, sugeridas por los participantes, que representan las memorias de las manifestaciones locales que actualmente están amenazadas, a saber: cuentos, leyendas e historias; pequeñas cosas, raíces y botellas; y bendiciones y oraciones. Tal conocimiento nos permite ver una tradición que está en gran riesgo de desaparecer y que busca en la naturaleza una conexión con la divinidad a través de la creencia en la dimensión espiritualsagrada de la naturaleza.

Con la información recopilada durante la primera etapa de la investigación de Renaud, se llevaron a cabo actividades colectivas, como talleres y conferencias ofrecidas en colaboración con las comunidades para diferentes grupos y grupos de edad, incluidos en especial niños y ancianos. Las actividades colectivas se llevaron a cabo en escuelas, centros sociales u otros espacios públicos. Además de la observación de las transformaciones y la ingeniería popular, como las formas de capturar el agua de la lluvia, los jardines medicinales, los videos de canciones y rituales, testimonios de leyendas populares, talleres de cine con niños, guiones y producciones también realizados por la población sobre la cultura local. Como por ejemplo, la relación con las temáticas socioambientales con las leyendas populares, difundidas hoy en día, las reuniones entre el investigador y la población de Jequitinhonha generaron talleres, juegos e intercambios, lo que resultó, finalmente, en una Investigación Acción Participativa, la IAP (FALS BORDA, 2007) cuyo protagonista no fue solo el investigadorproponente, pero principalmente toda la población involucrada y afectada por este intercambio de «sentipensar».

También de estas reuniones, Renaud desarrolló una serie de dibujos, como una forma de ayudar en la construcción de sus cuadernos de memorias de campo y reflexionar más directamente sobre el potencial de este lenguaje como una herramienta de comunicación intercultural y como una estrategia de acercamiento con los sujetos de investigación. Al ilustrar sus memorias, el artista-investigador guarda fragmentos de sus recuerdos y experiencias de encuentro con el campo, con las comunidades, con el pueblo.

Por lo tanto, al volver a admirar tales producciones de imágenes, el investigador 


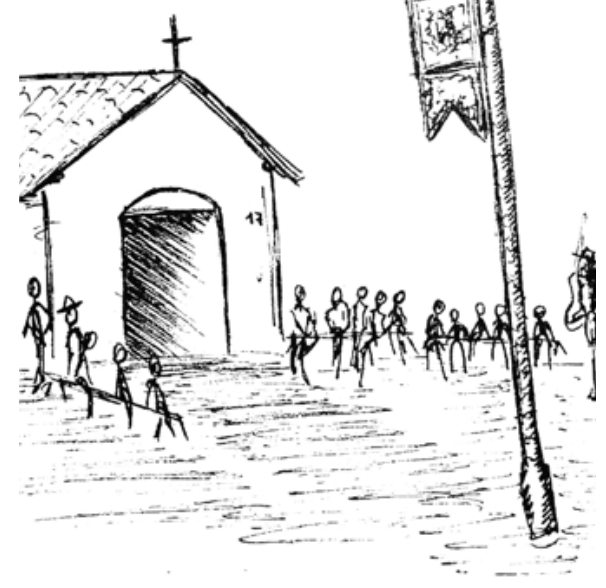

Figura 4. Pequeña Iglesia de Santos Reis en São Sebastião da Boa Vista, Chapada do Norte (MG). (Fuente: Daniel Renaud)

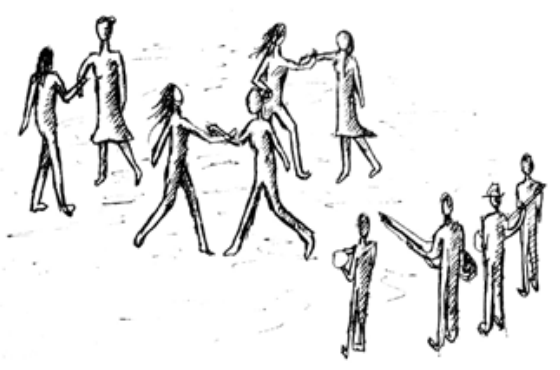

Figura 6. Mujeres ailando Vilão durante la Folia de Reis de Cachoeira do Norte. (Fuente: Daniel Renaud)

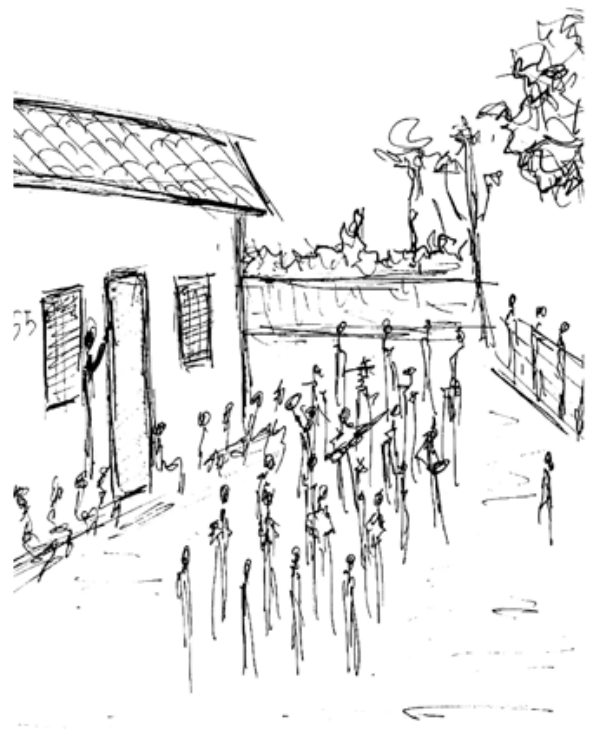

Figura 5. Folia de Reisen São Sebastião da Boa Vista, Chapada do Norte (MG). (Fuente: Daniel Renaud)

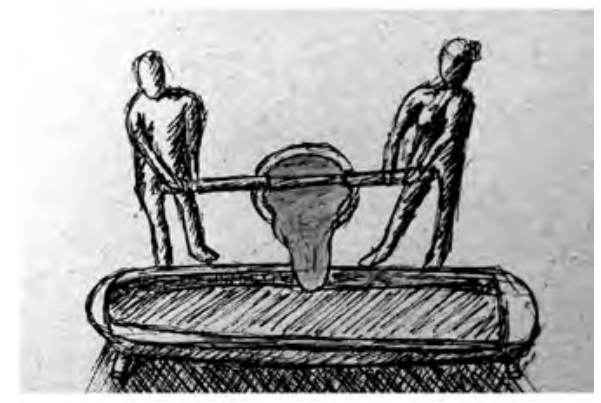

Figura 7. Sobre el arte de producir rapadura. (Fuente: Daniel Renaud) 
se conecta automáticamente con el momento en que ha experimentado contacto e inmersión en la realidad en cuestión. En la búsqueda de un lenguaje capaz de traducir el encuentro con el Brasil profundo, entendemos el dibujo como una posibilidad interesante no solo para ilustrar ciertos pasajes del texto; pero también como una herramienta para producir narrativas visuales; como instrumento de mediación intercultural; así como un dispositivo interesante para la construcción de cuadernos de campo más poéticos, vivos y hermosos.

Así, la producción de imágenes por un investigador-artista se revela como una gran potencia para la investigación con las comunidades, la investigación comprometida con la realidad social y la construcción de formas alternativas de comunicación popular. Por lo tanto, defendemos los cuadernos de memorias de campo con ilustraciones como una técnica de investigación que produce narrativas visuales e integra los temas del territorio con el campo del arte.

\section{Fotoescrevivencias: Narrativas Visuales del encuentro sensible con las poéticas de Maestra Lola de Colombia y Conceição Evaristo de Brasil}

La metodología de las fotoescrevivencias es una práctica dialógica dentro de la metodología participativa para una investigación socialmente comprometida con las luchas de la comunidad. Se basa en la fotografía como una producción narrativa visual contrahegemónica que rompe con los patrones estéticos y su uso para la dominación. Integrado con la idea de escrevivir de la maestra Conceição Evaristo (2006), la autora busca escribir ficción como si escribiera la realidad vivida del encuentro con los sujetos colectivos. En el fondo, en el fundamento de sus narraciones hay una experiencia, que era la de ella y la de sus compañeros, los negros, la diáspora africana, las mujeres en condiciones de opresión. Para Evaristo, escribir es perseguir a una escrevivencia, un concepto que brota de la unión de lo que se escribe con lo que se vive, hasta que no hay más separación. Por lo que busca la voz, la voz del hablante, para mezclarse con la de ella, para recordar la historia oral de su gente y su ancestralidad, Conceiçáo Evaristo nos inspira con su literatura.

La creación de la fotoescrevivencia comienza con la liberación de la escritura de la investigación cuantitativa académica, obtenida del ejercicio fundamental del movimiento: ir y venir, pasar de la teoría a la práctica, de lo subjetivo a lo concreto, del yo al otro, el proceso creador para romper con la forma única de producir ciencia (PELACANI, 20I8). Este proceso de creación artística-pedagógica parte de la reflexión en el ámbito de la maestría en Educación de Bárbara Pelacani, en su intercambio académico para Colombia 
encuentra nuevos caminos para la educación ambiental. La búsqueda y la inquietud fueron sus guías en los senderos por donde caminaba para romper con las estructuras epistemológicas dominantes. Con los compañeros del Grupo GEASur empezó a mirar otras posibilidades de producir conocimiento y en Colombia se sorprende con nuevas metodologías pedagógicas.

En la fotoescrevivencia desarrollada por Pelacani (20I8), las mujeres demarcan su posición, describen sus historias y forman a otras mujeres en el proceso de lucha en medio de los conflictos socioambientales que aparecen en las narrativas descritas. Para la autora, "contar su historia» es una estrategia de re-existencia comunitaria que dialoga con la pedagogía de los oprimidos y el ecologismo de los pobres. La narrativa visual se opone a la invisibilidad del otro, característica de las relaciones colonizador/ colonizado formadas en el sistema colonial moderno de producir conocimiento. La fotoescrevivencia es un proceso de construcción de autonomía, de práctica de la autoría y de la creatividad en la formación del investigador-educador, que permite la integración del conocimiento académico con el conocimiento popular.

Las palabras y las imágenes apuntan a un Sur metodológico, en este camino participativo que brota de la tierra; de los muros que nos limitan; de fuerza laboral disruptiva; de los cuartos de las mucamas; de las manos en la tierra; del conocimiento expuesto en forma de poesía, con palabras firmes, a veces gritadas, a veces invisibilizada. Un camino presente en las audiencias de teatro revolucionarias, en los cines socioambientales, en las reuniones comunitarias y lanzamientos de libros. Estamos expuestos, incluso si no se nos ve. El conocimiento del oprimido existe, mismo si no se escucha desde lo académico. La sordera de la academia, no significa que no se produce conocimiento desde los negros, desde las mujeres, desde los quilombos, desde los indígenas, desde los márgenes. Como nos enseña Conceição Evaristo, las mujeres negras son productoras de saberes únicos.

La propuesta de reunión de las sendas poéticas de Conceição Evaristo con la poesía pedagógica de la Maestra Lola está en la siguiente narración visual, el registro visceral en la forma de las fotoescrevivencias. Esta metodología fortalece la posición política de las mujeres de comunidades inmersas en conflictos socioambientales (PELACANI, 20I8).

En la fotoescrevivencia la autora nos brinda con su encuentro con la comunidad del Cauca Colombiano, del encantamiento con la «Pedagogía de la Corridez» de la maestra Lola. Una profesora que crea los procesos pedagógicos con los estudiantes, con la comunidad, con el territorio. Su pedagogía trae las artes como enfoque, como la orquestra de tarros, las bibliotecas vivas, los paseos a los ríos. El contacto con la naturaleza 


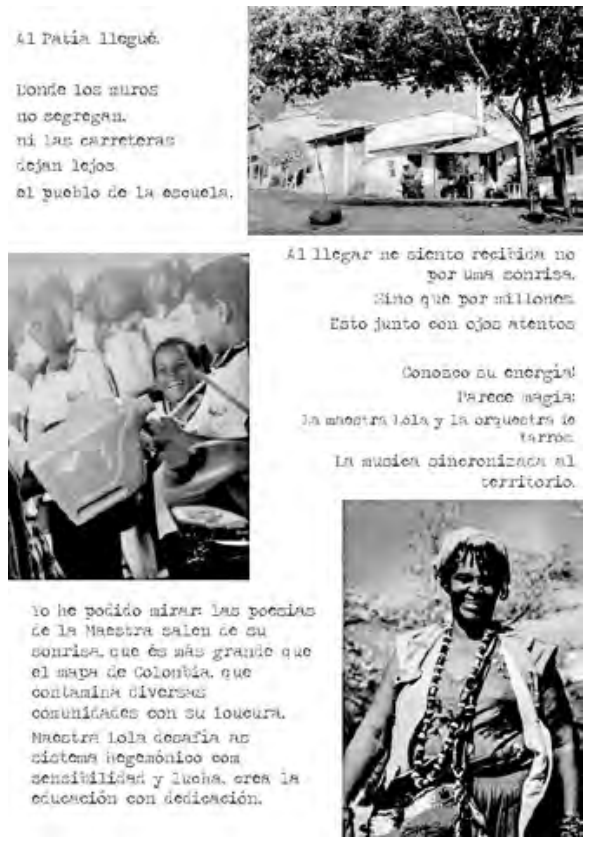

Figuras 8, 9 y 10. Fotoescrevivencia (Fuente: Bárbara Pelacani)

es parte de la educación propuesta. La fotoescrevivencia trae los sujetos para el diálogo ambiental, trae las sonrisas como procesos de producción de conocimiento, las miradas como poesía. Las maestras Lola y Conceição Evaristo, dos mujeres negras con sabiduría ancestral presentan la unión de arte y pedagogía, de sujetos colectivos, que no se separan con muros, ni con carreteras, ni con países. Son historias de mujeres que luchan por la vida de sus comunidades negras, que representan la fuerza sensible de las mujeres. Tal poder incentiva Pelacani a escrevivir y fotografar, el diálogo con las mujeres permite que una metodología dialógica presente resultados distintos para la universidad y para la investigación científica, no apenas un método, pero una reflexión epistemológica para la apertura de nuevas sendas poéticas desde el Sur.

\section{Exposiciones colectivas de arte: Procesos para derribar los muros de las universidades}

De la confluencia de los caminos de tantas investigaciones que pasan por procesos pedagógico-artísticos, empezó el deseo de exponer, de integrar senderos y territorios. Así, el Grupo GEASur rompió con la perspectiva solitaria sugerida por el sesgo académico tradicional. Los muros de la universidad, que nunca existieron en una investigación de educación ambiental basada en la comunidad, se cayeron, ¿cómo se almacenaría el proceso artísticopedagógico en documentos de tesis y disertación? Entonces, las exposiciones siguieron el flujo de lo pedagógico y de la arte, exponer los procesos de los investigadores, de los educadores y de los artistas para el público. Con una curación crítica y decolonial de los autores del presente trabajo seleccionaran obras artísticas con lenguajes únicos de Nuestra América Latina. Una narrativa alrededor de los trabajos resultó en exposiciones que abarcaran un público diverso, con presentaciones de clases universitarias, visitas guiadas, charlas con las artistas y debates, además de presentaciones de música. 
Las exposiciones «Terrumanidade, Terrexistencia y Territoriania: Irrigaciones interculturales» $\mathrm{y}$ «Hzorizontes», celebradas en 2019, en universidades y también en el espacio cultural Raízes del Brasil, en Río de Janeiro, que reúne el Movimiento de Pequeños Agricultores MPA, produjeron el diálogo del proceso de la investigación en educación ambiental con la creación en el campo del arte. En la exposición «Terrumanidade, Terrexistencia y Territoriania: Irrigaciones interculturales» participaron los artistas: Bárbara Fortes, Bárbara Pelacani, Celso Sánchez, López Ney, Daniel Renaud, Emerson Guerra, Jorge Chaves, Luísa Harduim, Marina Micas, Marrytsa Melo,Michele Sato, Ricardo Harduim, Susana Alegria, Tita Bevilaqua y Wallacy Coelho. En la exposición «Horizontes» participaron los artistas: Amanda Morais, Bárbara Pelacani, Casimiro de Paula, Celso Sánchez, Daniel Renault, Denise Adams, Emerson Guerra, Jean-François Simon, Jorge Chaves, Luan Hugolino, Michele Sato, Raiene Evangelista, Sallisa Rosa, Silas Evangelista, Tita Bevilaqua.

Los trabajos seleccionados para los eventos reunieron resultados y procesos de investigación de GEASur y de investigadores, artistas, educadores asociados. Las exhibiciones dieron visibilidad a las singularidades y misterios de las expresiones culturales sobrevivientes, comúnmente silenciadas o ignoradas por una cultura dominante, brillando así el brillo que aún brilla en los pueblos, quilombos, barrios bajos, favelas, terreiros, en los maestros y maestras campesinas, en los que los «otros» revelan una pieza de «nudos» que, aunque silenciados, gritan. Los lazos que forman este tejido entretejido de nosotros y entrenudos fertilizan este suelo latinoamericano o Abya Ayala, como lo llamaban los pueblos de este vasto continente, afirman que la humanidad y la existencia encarnan en la naturaleza y producen las confluencias y transfluencias que existen hoy en día.

Recuerdos bioculturales y suficiencia intimas en las reminiscencias del conocimiento ancestral, que re-existen y nos instan a emerger en nuestro derecho a existir y estar en nuestra humanidad. Por lo tanto, además de proporcionar momentos de disfrute, estas exhibiciones revelaron una disposición interdisciplinaria de la educación, el arte y los grupos sociales para participar socialmente, conectándose a una práctica pedagógica crítica y transgresora que re-articula las relaciones interculturales y ambientales en el medio ambiente. Son exposiciones de los paisajes brasileños y latinoamericanos.

\section{Consideraciones Finales}

Paulo Freire afirma que durante la investigación, el investigador educa y al mismo tiempo se educa a sí mismo en un movimiento permanente y dinámico (1981: 36). Helguera, a su vez, inspirado por esta percepción en acciones artísticas colaborativas, considera que la pedagogía 

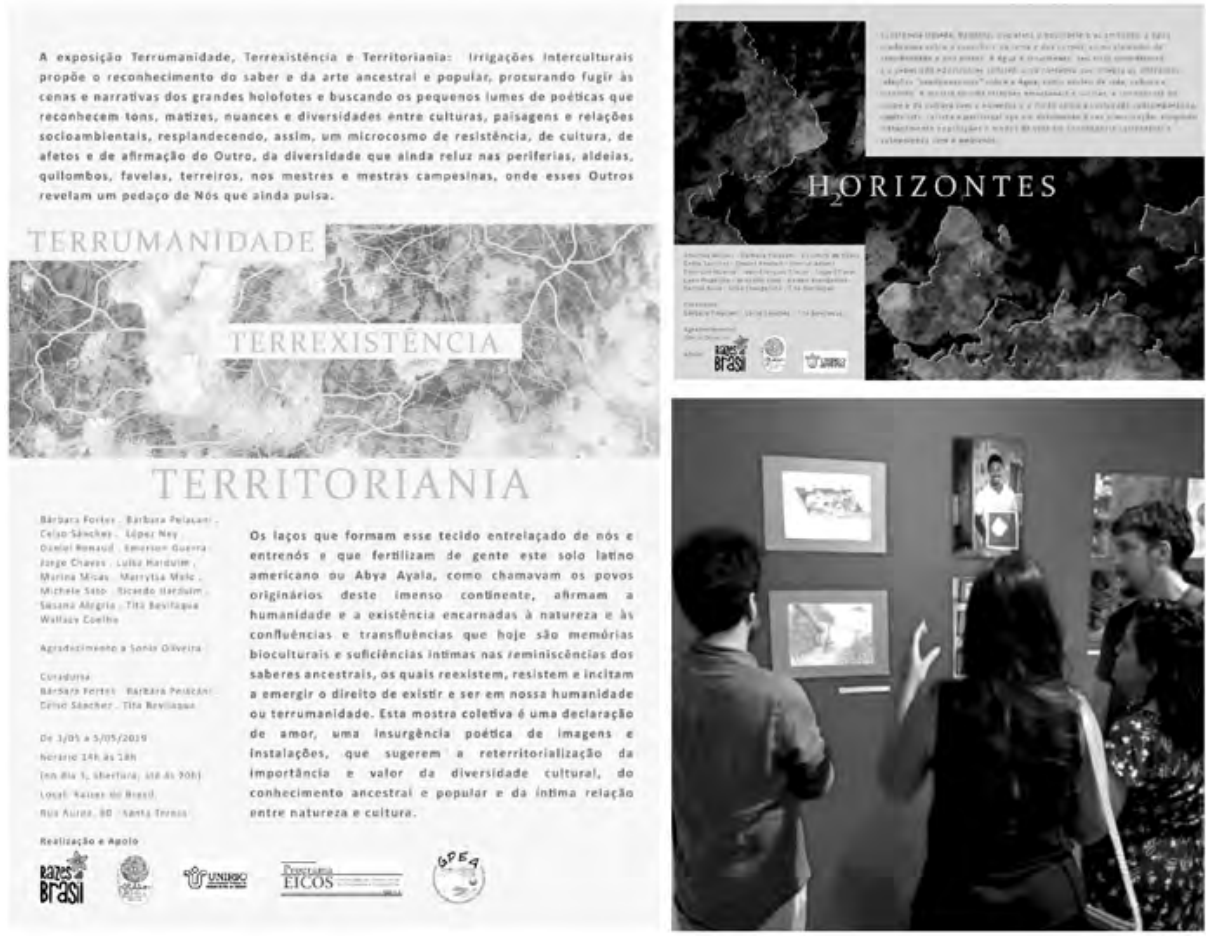

Figuras 11, 12, 13 y 14. exposición (Fuente: Patrícia Bevilaqua)

es un medio para generar diálogo y colaboración para la creación colectiva. Para el autor, el enfoque constructivo de la comunicación, incluso si es idealista, es una acción lógica porque propone la transformación del interlocutor, así como de sí mismo, en el proceso (20I2). Esta sintonización epistemológica y afinidad de las estructuras de acción permite la creación y la imaginación de las poéticas y poiésis de un presente y un futuro de «viabilidad inédita» (FREIRE, 1987: 53) $\mathrm{o}$, en otras palabras, de felicidad en el sentido colectivo, definido por Loureiro, para el cual «la libertad individual pasa por la libertad colectiva» (20I2: 69):

La felicidad se relaciona con la libertad existencial (ser no solo libre de algo, sino también libre de hacer algo) y la autonomía (condición de la libre decisión del individuo sobre qué hacer). Esto significa que el deseo de felicidad está vinculado a las necesidades humanas materiales $\mathrm{y}$ simbólicas (20I2: 38).

Una idea de felicidad que se relaciona, de esta manera, con el autoconocimiento, 
abierto a los flujos y también a la percepción del otro, el medio ambiente y su paisaje biológico, político y cultural. La autonomía con el compromiso, tanto individual como colectivo, de diseñar nuevos paradigmas sobre los fundamentos de la cosmovisión prevaleciente y formas de vida modernas, científicas, industriales y materialistas orientadas al crecimiento. Como propone la psicoanalista y filósofa Suely Rolnik, «Una forma de sentir el mundo, superando la red cultural del planeta capitalista, a través de una micropolítica activa que conduce al inconsciente colonial hacia una perspectiva relacional, heterogenética, singular y pluriversal» (ROLNIK, 20I5)

El camino poético de la metodología del Grupo GEASur sugiere así el rescate epistémico y vital de la condición terrenal y ecosistémica del ser humano en relación con el multiverso de conocimiento, culturas, ascendencia y eco-ontogénesis. Caminantes por la existencia del ser y por la certeza de que «todo ser humano es un artista», porque tiene la capacidad innata de transformar su entorno y crear; con la libertad de creación dirigida al trabajo socioecológico, como lo declaró el artista chamán Joseph Beuys (I985:I), los educadores-artistas-investigadores de GEASur buscan las venas abiertas de América Latina y todas las culturas ignoradas o incluso aniquiladas por colonialismo histórico y contemporáneo, para imaginar la creación de otras esculturas sociales, afectivas, colectivas, ambientales y culturales de mundos.

\section{Agradecimientos}

Agradecemos a la agencia financiadora Coordenação de Aperfeiçoamento de Pessoal de Nível Superior (CAPes) por la beca de estúdios concedidas a las autoras Bárbara Pelacani y Patrícia Bevilaqua, al Programa Eicos de la Universidad Federal de Río de Janeiro, a los investigadores del Grupo GEASur, en especial a la investigadora Sônia Terezinha que es parte fundamental del Grupo de Trabajo de exposiciones que fue nuestra inspiración y nuestra base para realizar las actividades pedagógicoartísticas. También agradecemos a los artistas de los territorios que crearon, durante los proyectos de campo del del Grupo geaSur, la imaginación de mundos y las posibles e infinitas esculturas socioambientales con arte.

\section{Referencias Bibliográficas}

- ACSELRAD, H. (2005) Presentación. En: La ligereza insostenible de la política ambiental: desarrollo y conflictos sociales y ambientales. Belo Horizonte: Autêntica. 
- ALA PLASTICA (2015). Iniciativa Biorregional. A Redefinição dos Espaços de Criação e Ação. Rio de Janeiro: Revista Mesa número 2, p 57-60.

- ARENDT, H (2007). A Condição Humana. Rio de Janeiro: Forense Universitária.

- BEUYS, J (1985). Falando Sobre o Próprio País: Alemanha III. Munique: Discurso do artista proferido no Münchner Daucmerspiele. Consultado 17 de novembro de 2019 em: www.historias. interativas.nom.br/lilith/pesquisa/beuys-lia.pdf

- BEVILAQUA, Patrícia Magalhães (2015). Escultura Varal Sobrevivências. Niterói: UFF. Consultado em 07/06/2020 em: http://www.artes.uff.br/dissertacoes/2015/2015-patriciabevilaqua.pdf

• BOURRIAUD, N (2009). Estética Relacional. São Paulo: Martins. - CAMARGO, Daniel Renaud (2014). Contos, Bênçãos e Mezinhas: Educação Ambiental Popular como Estratégia de Proteção dos Saberes Locais (monografia). Rio de Janeiro: Universidade Federal do Estado do Rio de Janeiro.

- CAMARGO, D. R. (2017). Lendas, Rezas e Garrafadas: Educação ambiental de base comunitária e os saberes locais no vale do Jequitinhonha. Dissertação (Mestrado em Educação) - Programa de Pós-Graduação em Educação. Rio de Janeiro: Universidade Federal do Estado do Rio de Janeiro.

- COSTA, R.N (2019) Imaginamundos: O cinema socioambiental na formação inicial de professores de ciências. Anais da VII Reunião de Antropologia da Ciência e da Tecnologia, Florianópolis. - EVARISTO, C. Becos da memória. Belo Horizonte: Mazza. 2016. - FALS BORDA, Orlando. Globalización y Segunda República. Cuadernos del Pensamiento crítico Latinoamericano. Consejo Latinoamericano de Ciencias Sociales. In: Hacia el socialismo raizal y otros escritos, Ediciones desde abajo, Capítulo III, pp.71 96, Bogotá, 2007.

- FORTES, B (2019). O direito de ficar e de existir: a educação ambiental, luta por moradia e o direito à cidade na vila autódromo. Dissertação de mestrado. Rio de Janeiro: Universidade Federal do Estado do Rio de Janeiro. 
- FREIRE, P (1987). Pedagogia do oprimido. Rio de Janeiro: editora Paz e Terra.

- FREIRE, P (1996). Pedagogia da autonomia: saberes necessários à prática educativa. São Paulo: Paz e Terra.

- HAESBAERT, Rogério y BRUCE, Glauco (2002). A Desterritorialização na Obra de Deleuze e Guattari. GEOgraphia, Niterói: UFF. v. 4, n. 7, p. 7-22.

- HELGUerA, P. et al (2011). Pedagogia no Campo Expandido. Porto Alegre: Fundação Bienal de Artes Visuais do Mercosul.

- HELGUERA, P (2012). Cruzando fronteiras entre educação, arte e política. O projeto da EscuelaPanamericanadelDesasosiego. São Paulo: Periódico Permanente, v. 1, n.1. Consultado 17 de novembro em: http://www.forumpermanente.org/revista/edicao-0/entrevistas/pablo-helguera

- ILLICH, I. (1985) Sociedade sem Escolas. Petrópolis: Editora Vozes, 127p.

- KASTRUP, V (2008). Estratégias de resistência e criação. Competência ética e estratégias de resistência. Rio de Janeiro: Centro Edelstein de Pesquisas Sociais, p.120-130. Consultado 2 de novembro de 2019 em: http://books.scielo.org/id/hwhw6/ pdf/guareschi-9788599662908-10.pdf

- KESTER, G (2004). Conversation Pieces: Community and Communication in Modern Art. California: UniversityofCalifornia Press. - KESTER, G (2006). Colaboração, Arte e Subculturas. São Paulo: Caderno VídeoBrasil número 02 - Arte Mobilidade Sustentabilidade - CAPÍTULO II, p 10 - 35. Consultado 30 de outubro em: www.sescsp.org.br/sesc/videobrasil/up/ arquivos/200611/20061117_130507_CadernoVB02_P.pdf

- LADDAGA, R (2006). Estética de laEmergencia. Buenos Aires: Adriana Hidalgo Editora.

- LEFF, E (2009). Ecologia, Capital e Cultura: a Territorialização da racionalidade ambiental. Petrópolis: Editora Vozes.

- LOUREIRO, CF (2012). Sustentabilidade e educação: um olhar da ecologia política. SaoPaulo: Cortez.

- MENEZES, A., SALGADO, S., RANGEL, J., PELACANI, B., STORTTI, M., SÁNCHEZ, C. (2019). Educação ambiental desde el Sur: 
Da ruptura com a perspectiva colonial em busca de outras relações sociedade-natureza. In.:Decolonialidades na Educação em Ciências. Monteiro, B. [et al.] - 1. Ed. - São Paulo: Editora Livraria da Física.

- MORIN. E et al. (2003) Terra-Pátria. Porto Alegre: Sulina.

- MUSEO DE LAS REMOCIONES (2018). Museu Vivo. Disponível em: <https://museudasremocoes.com/museu-vivo//>. Acesso em: 20 dez. 2018.

- OITICICA FILHO, C (2013). Encontros: Mário Pedrosa. Rio de Janeiro: Beco do Azougue.

- OITICICA, H (1968). Apolicapopotesis. Rio de Janeiro. Consultado 10 de novembro de 2019 em: http://www.itaucultural.org. br/aplicexternas/enciclopedia/ho/detalhe/docs/dsp_imagem. cfm?name=Normal/0534.69\%20f01\%20-\%20773.gif

- OITICICA, H (1986). Aspiro ao Grande labirinto. Rio de Janeiro: Editora Rocco.

- PELACANI, Bárbara. As lutas que educam na América Latina: A Educação Ambiental que emerge do conflito pela água em Cachoeiras de Macacu com um olhar desde a Colômbia. Dissertação (Mestrado em Educação) - Programa de Pós-Graduação em Educação, Universidade Federal do Estado do Rio de Janeiro, Rio de Janeiro, 2018.

- PELBART, Peter Pál. Vida Capital. Ensaios de Biopolítica. São Paulo: Iluminuras, 2003

- PROENÇA, R (2012). A Noção de Ambiental em Joseph Beuys, Hélio Oiticica e Robert Smithson. In: BUENO, M L. Sociologia das artes visuais no Brasil. São Paulo: editora Senac, p.253-267. - ROLNIK, Suely (2015). Pensar a Partir do Saber-do-Corpo. Uma Micropolítica para Resistir ao Inconsciente Colonial. São Paulo: Apresentação realizada na Casa do Povo - vídeo. Consultado em 28 de outubro de 2019 em: https://vimeo.com/173605359 - SÁNCHEZ, Celso; SALGADO, Stephanie Di Chira; OLIVEIRA, Sônia Terezinha (2020) Aportes da ecologia política para a construção de uma educação ambiental de base comunitária no contexto latino-americano: narrando a experiência de um curso de extensão universitária. Revista AMBIENTE \& EDUCAÇÃO. v. 25, n.1. 
- SANTOS, M (2006). A Natureza do Espaço. Técnica e Tempo. Razão e Emoção. São Paulo: Edusp.

- SOUZA SANTOS, B (2007). Para além do pensamento abissal: das linhas globais a uma ecologia de saberes. São Paulo: Novos estudos - Cebrap no.79. Consultado 28 de outubro de 2019 em: http://www.scielo.br/scielo.php?script=sci_arttext\&pid $=$ S0101-33002007000300004

- SOUZA SANTOS, B, et al. (2009). Epistemologias do Sul. Coimbra: Edições Almedina.

- STORTTI, Marcelo Aranda. (2019). Aprender a resistir e resistir para aprender: um estudo sobre a educação ambiental que emerge das lutas de atingidos pela indústria do petróleo no Rio de Janeiro. Tese (Doutorado em Educação) - Centro de Ciências Humanas e Sociais, Universidade Federal do Estado do Rio de Janeiro. Rio de Janeiro, p. 179.

- ULPIANO, Claudio (1988). Vídeo da aula: Pensamento e Liberdade em Espinoza. Centro Claudio Ulpiano. Consultado 30 de outubro em: http://vimeo.com/10348233 